\section{Related content}

- $\frac{\text { Simulation studies of the beam cooling }}{\text { process in presence of heating effects in }}$
$\frac{\text { the Extra Low ENergy Antiproton ring }}{(\text { ELENA) }}$
J. Resta-López, J.R. Hunt, O. Karamyshev
et al.
- Linac-based positron source and
$\frac{\text { generation of a high density positronium }}{\text { cloud for the GBAR experiment }}$
L Liszkay, P Comini, C Corbel et al.
- The AD and ELENA orbit, trajectory and
intensity measurement systems
R. Marco-Hernández, D. Alves, M.E.
Angoletta et al.

\section{Erratum: Simulation studies of the beam cooling process in presence of heating effects in the Extra Low ENergy Antiproton ring (ELENA)}

To cite this article: J. Resta-López et al 2015 JINST 10 E08001

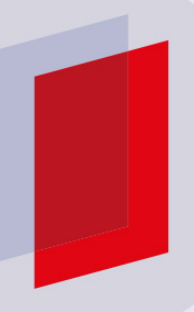

\section{IOP ebooks}

Bringing you innovative digital publishing with leading voices to create your essential collection of books in STEM research. Start exploring the collection - download the first chapter of every title for free. 


\title{
Erratum: Simulation studies of the beam cooling process in presence of heating effects in the Extra Low ENergy Antiproton ring (ELENA)
}

\author{
J. Resta-López, ${ }^{1}$ J.R. Hunt, O. Karamyshev and C.P. Welsch \\ Cockcroft Institute and The University of Liverpool, Sci-Tech Daresbury, \\ Keckwick Lane, Daresbury, Warrington, WA4 4AD, United Kingdom \\ E-mail: jrestalo@liverpool.ac.uk
}

ERRATUM TO: 2015 JINST 10 P05012

ABSTRACT: The Extra Low ENergy Antiproton ring (ELENA) is a small synchrotron equipped with an electron cooler, which is currently being constructed at CERN to further decelerate antiprotons from the Antiproton Decelerator (AD) from $5.3 \mathrm{MeV}$ to energies as low as $100 \mathrm{keV}$. At such low energies it is very important to carefully take contributions from electron cooling and beam heating mechanisms (e.g. on the residual gas and intrabeam scattering) into account. Detailed investigations into the ion kinetics under consideration of effects from electron cooling and heating sources have been carried out, and the equilibrium phase space dimensions of the beam have been computed, based on numerical simulations using the code BETACOOL. The goal is to provide a consistent explanation of the different physical effects acting on the beam in ELENA.

After reviewing the calculations, table 4 has been corrected, and here we show the correct values of the emittance growth due to rest gas scattering calculated using eq. (5.1). It is also necessary to clearly specify that these calculations have been performed assuming a rest gas consisting of $\mathrm{N}_{2}$ molecules with density (at room temperature) of $n=9.6 \times 10^{10} \mathrm{~m}^{-3}$. Furthermore, the corresponding slopes of the analytical line in figures 4 and 5 have also been corrected consistently. This correction does not affect the subsequent discussion and the conclusions are still valid.

\footnotetext{
${ }^{1}$ Corresponding author.
} 
Table 4. Emittance growth rate results for ELENA due to rest gas scattering with vacuum pressure $3 \times$ $10^{-12}$ Torr and assuming $100 \% \mathrm{~N}_{2}$ residual gas.

\begin{tabular}{|l|c|c|}
\hline Model & $\begin{array}{c}d \epsilon_{\mathrm{rms}} / d t[\mu \mathrm{m} / \mathrm{s}] \\
(\text { at } p=35 \mathrm{MeV} / c)\end{array}$ & $\begin{array}{c}d \epsilon_{\mathrm{rms}} / d t[\mu \mathrm{m} / \mathrm{s}] \\
(\text { at } p=13.7 \mathrm{MeV} / c)\end{array}$ \\
\hline BETACOOL & 0.015 & 0.21 \\
Analytical formula, eq. (5.1) & 0.011 & 0.18 \\
\hline
\end{tabular}
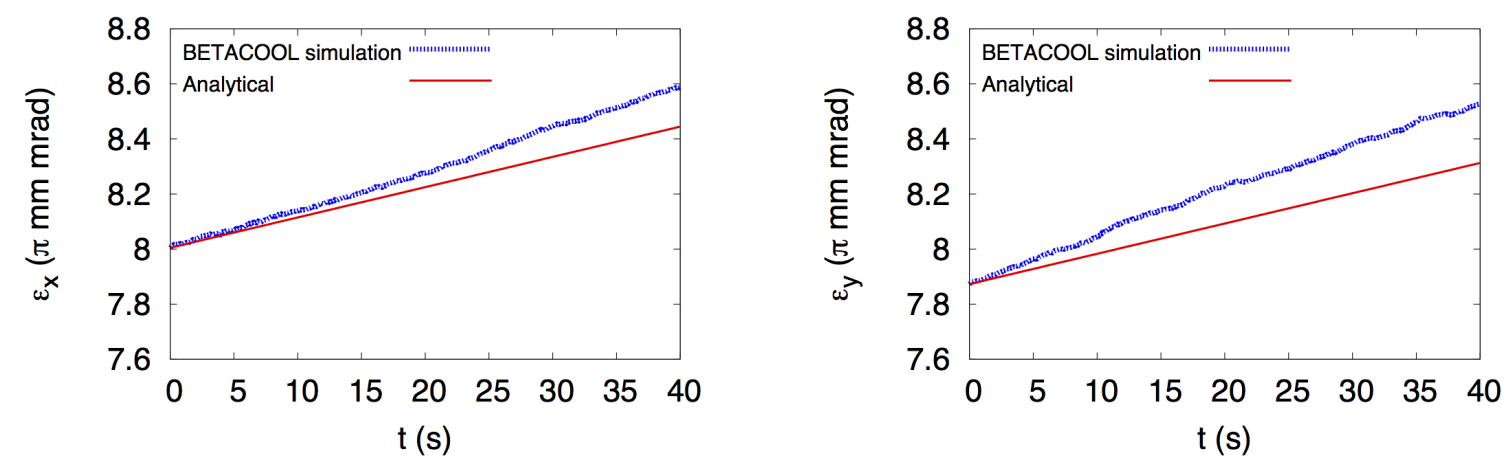

Figure 4. Horizontal (left) and vertical (right) emittance evolution due to rest gas scattering for an ELENA antiproton beam of $p=35 \mathrm{MeV} / c$. The blue line represents the average curve over 10 realisations simulated with BETACOOL. The red line is the analytical estimate. No cooling is applied.
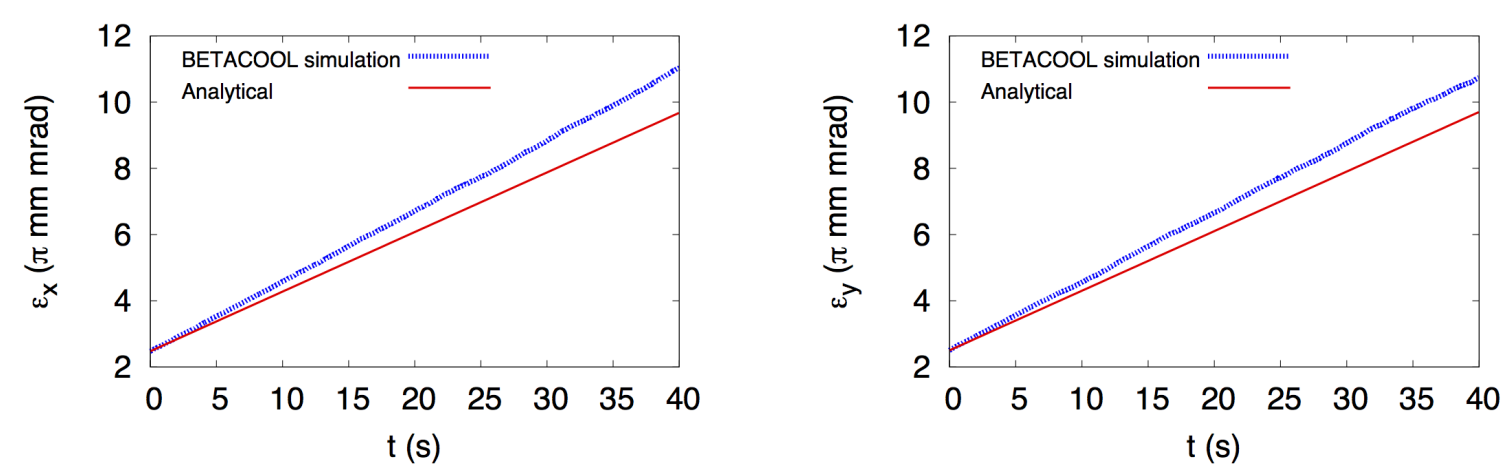

Figure 5. Horizontal (left) and vertical (right) emittance evolution due to rest gas scattering for an ELENA antiproton beam of $p=13.7 \mathrm{MeV} / c$. The blue line represents the average curve over 10 realisations simulated with BETACOOL. The red line is the analytical estimate. No cooling is applied. 